\title{
Direito Sanitário Aplicado Às Áreas Contaminadas ${ }^{(*)}$
}

\author{
HEALTH LAW APPLIED TO CONTAMINATED AREAS
}

Helita Barreira Custódio( ${ }^{(\star \star)}$

\section{RESUMO}

O Direito Sanitário e as questões relacionadas ao meio ambiente interessam a todos, pois estão vinculados à preservação da vida e sua qualidade. A revisão da legislação denota a necessidade de concretização das normas já existentes e demonstra, também, que a legislação não é insuficiente. A educação ambiental pode ser uma forma de sensibilizar a sociedade sobre a importância da preservação do meio ambiente. A preservação deve ser pensada, em conjunto, especialmente com a atividade econômica, de modo a promover o desenvolvimento equilibrado.

\section{Palavras-chave}

Direito Sanitário; Legislação; Saúde Ambiental; Saúde Pública.

\section{ABSTRACT}

Health Law and questions related to the environment interest all, at least because the preservation of life and its quality are both closely related to them. The revision of the legislation denotes the need of achievement of the already existing norms and demonstrates, also, that the legislation is not insufficient. Environmental education can be a form to sensitize the society on the importance of the preservation of the environment. The preservation must be thought as an ensemble, especially with the economic activity, in order to promote an equilibrated development.

(*) Texto elaborado a partir de palestra proferida, em 27 de outubro de 2004, durante 0 " $3^{9}$ Seminário Estadual Áreas Contaminadas e Saúde: o Olhar e o Papel da Universidade", promovido pelo Centro de Vigilância Sanitária, pela Faculdade de Saúde Pública e Faculdade de Medicina da USP, nos dias 27 e 28 de outubro de 2004, em São Paulo.

$\left.{ }^{\star \star}\right)$ Doutora em Direito e Professora "Livre-Docente" pela Universidade de São Paulo-USP; Aperfeiçoamento em Administração Pública com especialização em Direito Urbanístico pela Universidade de Roma "LA SAPIENZA". Recebido em 8.3.06. Aprovado em 5.5.06. 


\section{Key words}

Environmental Law; Health Law; Health Legislation; Public Health.

\section{INTRODUÇÃO}

Nessa breve nota introdutória, para melhor compreensão do relevante tema sobre Direito Sanitário aplicado às áreas contaminadas com notórios efeitos lesivos ao meio ambiente, à saúde ambiental, à saúde pública e à vida, direta e indiretamente relacionado com as políticas sanitária, ambiental, econômica, agrícola e a urbana, torna-se oportuna a apresentação de algumas noções, notadamente sobre meio ambiente e saúde.

Dentre outros conceitos, em razão dos diversos elementos componentes do patrimônio ambiental e das respectivas leis naturais e humanas, considera-se meio ambiente o conjunto tanto de circunstâncias e de relações recíprocas reguladas pelas leis naturais de ordem física, química e biológica, como de fatores socioeconômicos e culturais disciplinados pelas leis humanas integrantes do Direito Positivo que, de forma vinculada e interdependente, asseguram condições favoráveis de existência, desde a concepção, a germinação ou qualquer outra circunstância originária, o nascimento, desenvolvimento, preservação e continuidade da vida saudável, em seus diversos ciclos normais evolutivos, da pessoa humana e dos demais seres vivos (animais, vegetais e microorganismos em geral).

Trata-se de noção abrangente, pois compreende todos os bens ou recursos ambientais, tanto os naturais (vivos e não vivos, ar, águas em geral, fauna, flora, solo com seu subsolo, alimentos, luz solar, energia, silêncio ambiental) típicos do meio ambiente natural, como os sociais (relacionados com as atividades socioeconômicas, políticas, agrícolas, urbanísticas, industriais, habitacionais, profissionais, sanitárias, religiosas, educacionais, recreativas, de transportes) e os bens culturais (compreendidos todos os bens de valor cultural, materiais e imateriais, integrantes do patrimônio cultural) típicos do meio ambiente humano, caracterizados por interações ou interrelações com outros meios e por progressiva integração ajustável às novas exigências de cada momento.

O meio ambiente saudável, em sua ampla noção abrangente de bens ou recursos ambientais juridicamente protegidos e indispensáveis à sadia qualidade ambiental, propícia à vida em todas as suas formas, além de ser considerado "um patrimônio público a ser necessariamente assegurado e protegido" no interesse de todos (Lei n. 6.938, de 31 de agosto de 1981, art. $\left.2^{\circ}, \mathrm{I}\right)$, constitui, por expressa determinação fundamental (CF, art. 225), direito 
de todos, impondo-se ao Poder Público e à coletividade o dever de defendêlo e preservá-lo ao pleno bem-estar das presentes e futuras gerações ${ }^{(1)}$.

Além de outras noções científico-doutrinárias, em seu amplo sentido jurídico, considera-se saúde um bem público de interesse nacional, caracterizado como o estado de pleno bem-estar físico ou biológico, psíquico ou mental, social (em seus diversos aspectos educacionais, econômicos, familiares, espirituais, morais), cultural e ambiental da pessoa humana individual, coletiva e publicamente considerada. Em resumo, a saúde constitui um bem público constitucionalmente assegurado, garantido e protegido ao pleno bem-estar de todos. Em razão das desafiantes questões sanitárias de abrangentes áreas contaminadas prejudiciais à saúde humana e aos seres vivos em geral, trata-se de noção vinculada a um complexo de ações harmônicas, prioritárias, permanentes, preventivas e repressivas, ajustáveis ao equilibrado estado de salubridade ambiental, em progressivas condições favoráveis à promoção, defesa, proteção e recuperação e à melhoria e preservação da saúde ambiental, da saúde pública e da vida ${ }^{(2)}$.

A saúde, em sua ampla noção, constitui, por expressa determinação constitucional, direito de todos e dever do Estado (União, Estados, Distrito Federal e Municípios), com a participação da coletividade (pessoas físicas e jurídicas de direito privado), às ações e aos serviços para sua promoção, proteção, recuperação, melhoria e preservação (CF, art. 196). Trata-se de noção jurídica compatível com a ampla noção da Organização Mundial de Saúde, segundo a qual, superado o conceito tradicional e condicionado à falta de enfermidades, em razão das contínuas gravidade e ampliação das "moléstias de civilização", como aquelas decorrentes de notórias áreas contaminadas, considera-se saúde "o estado de completo bem-estar físico, mental e social, e não apenas a ausência de moléstias e enfermidades"(3).

Não obstante o dever constitucional do Estado para a proteção da saúde pública indispensável à continuidade da vida saudável como inviolável direito fundamental de todos (CF, arts. 5, 196), na prática, as atividades humanas, notadamente as econômicas perigosas com os respectivos resíduos, lixos ou rejeitos em geral (incluídos os hospitalares), vêm contaminando, de forma preocupante, imensas áreas, com variadas e crescentes fontes de poluição do ar, das águas superficiais e subterrâneas, do solo e subsolo,

(1) Reporta-se ao nosso trabalho Direito à saúde e problemática dos agrotóxicos. Revista de Direito Sanitário, São Paulo, v. 2. n. 3, p. 11, nov. 2001.

(2) Reporta-se ao nosso trabalho. Id. Ibid., p. 12.

(3) CHARBONNEAU, J. P.; RODES, M. Ecologia social. In:ENCICLOPÉDIA de Ecologia. São Paulo: EPU-EDUSP-SP, 1979. p. 423, 433. No Direito Comparado, define-se a saúde como "uma condição de harmônico equilibrio funcional, físico e psíquico do indivíduo, dinamicamente integrado no seu ambiente natural e social", SANGIULIANO, Rosanna (a cura di). Direito sanitario e servizio sanitario nazionale. 16. ed. Napoli: Simone, 2002. p. 7; CODE de L'Environnement. 6. ed. realisée avec le concours de Jean Lamarque. Paris: Dalloz, 1998, com as vinculadas normas legais e regulamentares do "Code de la Santé Publique", do "Code de l'Urbanisme", dentre outras normas. 
poluição sonora, visual ou paisagística, poluição atômica, nuclear ou radioativa, poluição lesiva à fauna e à flora em geral, poluição por agrotóxicos, poluição dos alimentos, tudo em preocupante lesão ao meio ambiente saudável, à saúde ambiental, saúde pública e à vida(4).

Tais desafiantes questões de áreas contaminadas impõem, além das medidas repressivas e recuperadoras relacionadas com as contaminações atuais, obrigatórias medidas preventivas notadamente de informação ambiental, educação ambiental e conscientização pública para participação ativa tanto do Poder Público como da coletividade no sentido de evitar, eliminar ou reduzir os efeitos danosos da contaminação em defesa e preservação do meio ambiente saudável, da saúde ambiental, da saúde pública e da vida, no legítimo interesse de todos.

\section{DIREITO SANITÁRIO: NOVO RAMO DO DIREITO EM PERMANENTE DEFESA DA SAÚDE PÚBLICA}

Para melhor compreensão do novo e relevante ramo do Direito Sanitário em permanente defesa da saúde pública, destacam-se, dentre outros conceitos, princípios e normas aplicáveis ao oportuno tema, os seguintes:

Visando ao contínuo reavivamento da conscientização do Poder Público e da coletividade em geral para sua participação ativa na defesa e preservação do meio ambiente saudável e da saúde pública, é sempre necessário recordar que se considera Direito um conjunto de princípios e normas de caráter obrigatório com as respectivas sanções, impostos pelo Poder Público competente, no sentido de regular as ações, condutas, atividades ou relações das pessoas, individual, coletiva ou publicamente consideradas, na vida em sociedade, bem como manter a harmonia ou o equilíbrio entre interesses diversos e a paz social, no legítimo benefício de todos.

Como um conjunto de princípios e normas obrigatórios de conduta social, mediante sanção, para a ordem e o equilíbrio de interesses na própria sociedade, a finalidade fundamental do Direito "é servir à vida, regular a vida"(5), como inviolável direito fundamental (CF, art. 5), garantindo condições de tranqüilidade ambiental e paz social. O Direito considerado como indispensável "conjunto de regras de conduta social", tem o "preciso fim

(4) BRASIL. Presidência da República. CIMA. O Desafio do Desenvolvimento Sustentável Relatório do Brasil para a Conferência da ONU sobre Meio Ambiente e Desenvolvimento, com a demonstração de graves impactos ambientais nas zonas urbanas com sua periferia e rurais de todas as Regiões do País. Brasília: Imprensa Nacional, 1991. p. 129 e ss. Neste sentido, reporta-se aos nossos trabalhos: Princípios constitucionais da Proteção das Águas. Revista de Direitos Difusos, São Paulo, v. 4, n. 16, p. 2127-2146, nov./dez. 2002; Direito ambiental e questōes jurídicas relevantes. Campinas: Millennium Ed., 2004. p. 400 e 22. No prelo.

(5) MAXIMILIANO, Carlos. Hermenêutica e aplicação do direito. 9. ed. Rio de Janeiro: Forense, 1979. p. 153-154. 
fundamental" de "assegurar a pacífica convivência" de ordem social que só será garantia mediante "a realização de dois objetivos essenciais: aquele da certeza do direito e aquele de certeza da observância do próprio direito"(6).

De forma compatível com a abrangente noção do Direito, considera-se Direito Sanitário um conjunto de princípios e normas gerais, especiais, complementares e excepcionais de caráter obrigatório com as respectivas sanções, impostos pelo Poder Público competente, os quais regulam as ações e os serviços públicos e privados de saúde individual, coletiva ou publicamente considerada, mediante obrigatório planejamento compreendido de medidas regulamentares, fiscalizadoras, controladoras e preventivas, por parte do Poder Público, bem como de planos ou programas de adequada execução diretamente da Administração Pública ou através de pessoas físicas ou jurídicas de direito privado.

As pessoas responsáveis pelas ações e pelos serviços públicos de saúde devem, obrigatoriamente, observar as diretrizes constitucionais ao atendimento integral, com prioridade para as atividades preventivas vinculadas à execução de ações e serviços de vigilância sanitária e epidemiológica, de saneamento básico, de fiscalização e controle de alimentos e bebidas em geral, de águas para consumo humano, de substâncias e produtos psicoativos, tóxicos e radioativos, de proteção do meio ambiente saudável, nele compreendido o do trabalho, dentre outras atribuições essenciais impostas por expressas diretrizes e normas constitucionais (CF, arts. 196 a 200) e legais (Lei n. 8.080, de 19 de setembro de 1990) aplicáveis.

O Direito Sanitário tem como objetivos, dentre outros, a promoção, a proteção, a defesa, a recuperação, a melhoria e a preservação da saúde ambiental e da saúde pública (nesta compreendida a saúde individual, coletiva, comum ou difusamente considerada). Como novo ramo do Direito em defesa e preservação da saúde pública, o Direito Sanitário se inter-relaciona notadamente com o Direito Ambiental, o Direito Agrário, o Direito Urbanístico e o Direito Econômico, todos constitucionalmente consolidados e indispensáveis à sadia continuidade da vida das gerações presentes e futuras.

Implícita e expressamente previsto nas normas constitucionais anteriores $^{(7)}$, o Direito Sanitário, foi reafirmado, ampliado e consolidado pela vigente

(6) BARILE, Paolo. Istituzione di diritto pubblico. 2. ed. Padova: CEDAM, 1975. p. 3; BEVILÁCQUA, Clóvis. Teoria geral do direito. 7. ed. Rio de Janeiro: Francisco Alves, 1955. p. 11.

(7) Em nosso Direito Positivo, as primeiras normas fundamentais de Direito Sanitário foram previstas na Constituição do Império de 1824, com a garantia da inviolabilidade dos direitos civis e da saúde dos cidadãos (art. 179, XXIV). Na $1^{\text {a }}$ Constituição da República de 1891, as normas sobre saúde foram previstas implicitamente na declaração de direitos (art. 72). Tais normas, a partir da Constituição de 1934, implícitas no Capítulo dos direitos e garantias fundamentais (CF/1934, art. 113; CF/1937, art. 122), passaram a constituir matéria de competência legislativa, ora concorrente da União e dos Estados para "cuidar da saúde e assistência públicas" (CF/1934, art. 10,11), ora privativa da União para estabelecer "normas fundamentais da defesa e proteção da saúde, especialmente da saúde da criança" (CF/1937, art. 16, XXVII). Em progressiva evolução, a partir da Constituição de 1946, as normas sobre saúde, agora 
Magna Carta, em razão das progressivas exigências notadamente socioeconômicas, agrícolas, urbanísticas e sanitário-ambientais.

Evidentemente, a Constituição Federal de 1988, além de garantir a inviolabilidade do direito à vida, incluída a inviolabilidade do direito à saúde (CF, art. $\left.5^{\circ}\right)$, introduziu, de forma inovadora, a competência exclusiva ou específica da União a fim de instituir diretrizes para o desenvolvimento urbano, inclusive habitação, saneamento básico e transportes urbanos, explorar os serviços e as instalações nucleares de qualquer natureza, atendidos os princípios e as condições constitucionais, bem como, sob regime de concessão ou permissão, autorizar "a utilização de radioisótopos para a pesquisa $e$ usos medicinais, agrícolas, industriais", dentre outros (CF, art. 21, XX,

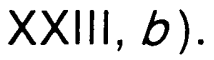

Além da competência privativa da União para estabelecer normas gerais no âmbito da legislação concorrente ou suplementar sobre assunto de interesse nacional, estadual, distrital e municipal, em matéria de Direito Sanitário, a vigente Constituição define:

a) A competência concorrente da União, dos Estados e do Distrito Federal (incluída a dos Municípios, implícita e expressamente, por se tratar de matéria de interesse local, CF, art. 24, XII, c/c. art. 30, I, VII) para legislar sobre a proteção e defesa da saúde (CF, art. 24, XII, §§ 1ํa 4º);

b) A competência comum da União, dos Estados, do Distrito Federal e dos Municípios, de caráter executivo (sem prejuízo da competência legislativa), para cuidar da saúde e assistência pública (CF, art. 23, II); proteger o meio ambiente e combater a poluição em qualquer de suas formas (CF, art. 23. VI); preservar as florestas, a fauna e a flora (CF, art. 23, VII); promover a melhoria das condições habitacionais e de saneamento básico, executar as ações de vigilância sanitária, epidemiológica e da saúde; fiscalizar, inspecionar e controlar o teor nutricional dos alimentos, das bebidas e águas para consumo humano, bem como controlar e fiscalizar todas as providências sobre as substâncias e os produtos psicoativos, tóxicos e radioativos (CF, art. 23, IX, c/c. art. 200, II, IV, VI, VII); registrar, acompanhar e fiscalizar as concessões de direitos de pesquisa e exploração de recursos hídricos e minerais em seus respectivos territórios $(\mathrm{CF}$, art. $23, \mathrm{XI})$; assegurar os direitos relativos à saúde (CF, art. 194); garantir, mediante políticas sociais e econômicas que visem à redução do risco de doença e de outros agravos, a promoção, a proteção, a defesa, a recuperação, a melhoria e a preservação da saúde, definida como direito de todos e dever do Estado (União, Estados, Distrito Federal e Municípios), além da prioridade para as

expressamente garantidas na "inviolabilidade dos direitos concernentes à vida" (CF/1946, art. 141; CF/ 1967, art. 150; $E C$ n. $1 / 1969$, art. 153; $C F / 1988$, art. $\left.5^{\circ}\right)$, foram reafirmadas como matéria de competência

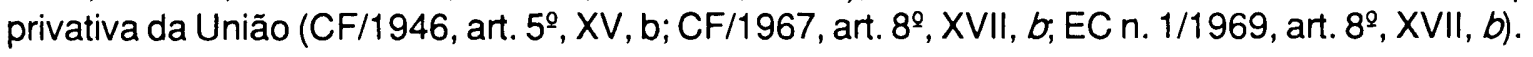


atividades preventivas, em caráter permanente (CF, arts. 196, 197, II, 198, 200, I a VII, 225, § 1ํ, V, VI, VII).

c) A competência suplementar das Unidades da Federação para legislar sobre questões específicas não previstas nas normas gerais de competência da União, como, dentre outras, questões ambientais, alimentares, sanitárias, para o preenchimento dos vazios das normas existentes, de forma compatível com as respectivas peculiaridades, observadas as normas gerais de competência privativa ou concorrente da União ou do Estado, de acordo com as circunstâncias de cada caso concreto (CF - competência suplementar: dos Estados, arts. 22, parágrafo único, 24, $\S 2^{\circ}, 25, \S 1^{\circ}$; do Distrito Federal, art. $32, \S 1^{\circ}$, c/c. arts. 22, parágrafo único, 30, I1; dos Municípios, art. 30, II).

No campo da competência suplementar, as normas de natureza mais restritiva prevalecem, sempre, para atender às peculiaridades estaduais, distritais e municipais, de forma compatível tanto com o princípio da autonomia independente e harmônica das Unidades da Federação como com os objetivos constitucionais e legais em defesa e preservação da saúde ambiental, da saúde pública e da vida.

d) Princípios gerais da atividade econômica a serem observados para a conciliação do desenvolvimento socioeconômico, agrícola e urbanístico com a preservação da sadia qualidade ambiental propícia à saúde ambiental, à saúde pública e à vida (CF, arts. 170, III, V, VI, 182, $\S \S 1^{\circ}$ a $4^{\circ}, 186$ a $188, \mathrm{c} / \mathrm{c}$. arts. 23, II, VI, VII, IX, XI, 225, §§ $1^{\circ}, \mathrm{IV}, \mathrm{V}, \mathrm{VI}, \mathrm{VII}$, $\left.2^{\circ}\right)$, tudo visando a proteger a vida presente e futura, como inviolável direito fundamental da pessoa humana individual, coletiva e publicamente considerada.

\section{DEVERES E RESPONSABILIDADES DO PODER PÚBLICO E DA COLETIVIDADE}

Expressas são por força dos princípios e das normas constitucionais e legais vigentes, as competências de todas as Unidades da Federação, de forma harmônica e integrada, para legislar sobre matéria de interesse dos respectivos territórios, conhecer, entender, defender, cumprir ou executar, adequar, atualizar e aplicar as disposições constitucionais e legais correlatas, bem como fiscalizar e controlar os serviços correspondentes, de forma permanente, no sentido de evitar, reduzir ou eliminar os efeitos lesivos da poluição em qualquer de suas formas contaminantes, de maneira ajustável às progressivas exigências socioeconômicas e ambientais e sanitárias ao bem-estar de todos.

Conseqüentemente, expressos são os deveres e as responsabilidades impostos à Administração Pública direta e indireta de qualquer dos 
Poderes da União, dos Estados, do Distrito Federal e dos Municípios, ou de qualquer pessoa física ou jurídica de direito privado prestadora ou realizadora de ações e serviços públicos de saúde, para o desempenho, de forma permanente, preventiva e eficaz, de suas atribuições, sempre sujeita à obrigatória obediência aos princípios da legalidade, impessoalidade, moralidade, publicidade, probidade, eficiência, dentre outros, no interesse público (CF, art. 37).

Em matéria de agricultura, saneamento básico, vigilância sanitária e epidemiológica, saúde e meio ambiente, asseguradas pelos princípios e normas constitucionais e legais, integrantes, respectivamente, do Direito Agrário, do Direito Sanitário e do Direito Ambiental, tais deveres e responsabilidades, além de inerentes aos Poderes Públicos (CF, art. 37, $\S 4^{\circ}, 5^{\circ}, 6^{\circ}$, c/c. art. 21, XXIII, c; Lei n. 8.429, de 2 de junho de 1992), estendem-se à coletividade (pessoas físicas ou jurídicas de direito privado, com ou sem fins lucrativos), por expressas determinações constitucionais e legais, demonstrando-se que todas as pessoas jurídicas de direito público e as de direito privado prestadoras de serviços públicos, bem como as pessoas físicas e jurídicas de direito privado competentes são responsáveis, de acordo com as circunstâncias de cada caso concreto, pelos danos decorrentes das respectivas atividades perigosas.

Evidencia-se, portanto, que o descumprimento das vigentes imposições constitucionais e legais citadas, com as conseqüentes contaminações agrícolas e alimentares, as lesões ao meio ambiente, à saúde ambiental, à saúde pública e à vida, sujeitará a autoridade pública, o servidor ou qualquer agente prestador de serviço público infrator, ou qualquer pessoa física ou jurídica de direito privado infratora, às responsabilidades e respectivas sanções políticas, administrativas, disciplinares, civis, penais ou criminais aplicáveis de acordo com as normas constitucionais ou legais violadas e as circunstâncias de cada caso concreto. Não resta dúvida de que os básicos princípios e normas particularmente constitucionais devem tornar-se, cada vez mais, "efetivos e eficientes", uma vez que a Constituição, sendo "a égide da paz, a garantia da ordem", tem "em mira os fins", fornece "meios para atingi-los", devendo os responsáveis "descobri-los e aplicá-los" ao bem de todos ${ }^{(8)}$. Assim: "É necessário compreendê-la corretamente, saber o que é a Constituição" e como esta "deve ser elaborada e aplicada para que possa atingir suas finalidades"(9) ao legítimo bem-estar de todos e à paz social.

O Direito Sanitário aplicado às áreas contaminadas e lesivas à saúde ambiental, à saúde pública e à vida é matéria notória e reconhecidamente vasta, complexa e de repercussões crescentes; conclui-se que enorme é o desafio das áreas contaminadas, em face do inquietante agravamento da

(8) MAXIMILIANO, Carlos. op. cit., p. 306, 312.

(9) DALLARI, Dalmo de Abreu. Constituição e constituinte. 3. ed. São Paulo: Saraiva, 1986. p. 14. 
degradação dos recursos ambientais de forma geral e da contaminação dos alimentos, das bebidas e das águas de forma particular, em razão do emprego de técnicas, métodos ou do uso excessivo e incontrolável de substâncias e produtos psicoativos, agrotóxicos, aditivos diversos e radioativos de comprovados riscos e danos à vida, à qualidade de vida, à saúde pública e ao meio ambiente, tanto nos âmbitos local, distrital e estadual como regional (dois ou mais Estados) e nacional(10).

Evidentemente, é preocupante a realidade atual caracterizada tanto por notórias lesões contra o meio ambiente saudável, a saúde ambiental, pública e à vida como por agravantes questões sanitárias decorrentes de áreas contaminadas em confronto com as respectivas fundamentações constitucionais e legais aplicáveis, sendo inadiável a necessidade do real cumprimento das normas jurídicas correlatas e as inadiáveis e permanentes providências em prol da educação para a plena conscientização pública indispensável às eficientes medidas notadamente preventivas sobre a permanente necessidade de reflexões, pesquisas científicas, tecnológicas e jurídicas, de cooperação, participação, contribuição e de co-responsabilidade, como providências obrigatórias e irrenunciáveis à conciliação do desenvolvimento socioeconômico com a preservação da sadia qualidade ambiental propícia à saúde ambiental, pública e à vida presente e futura e ao equilibrado desenvolvimento nacional.

\section{REFERENCIAS}

BARILE, Paolo. Istituzione di diritto pubblico. 2. ed. Padova: CEDAM, 1975. BEVILÁCQUA, Clóvis. Teoria geral do direito. 7. ed. Rio de Janeiro: FrancisCo Alves, 1955.

BONTEMPO, Márcio. Relatório ORION: denúncia médica sobre os perigos dos alimentos industrializados e agrotóxicos. 3. ed. Porto Alegre: L \& PM, 1986.

BRASIL. Presidência da República. CIMA. O Desafio do Desenvolvimento Sustentável - Relatório do Brasil para a Conferência da ONU sobre Meio Ambiente e Desenvolvimento, com a demonstração de graves impactos ambientais nas zonas urbanas com sua periferia e rurais de todas as Regiões do País. Brasília: Imprensa Nacional, 1991.

CHARBONNEAU, J. P.; RODES, M. Ecologia social. In: ENCICLOPÉDIA de Ecologia. São Paulo: EPU-EDUSP-SP, 1979.

CODE de L'Environnement. 6. ed. realisée avec le concours de Jean Lamarque. Paris: Dalloz, 1998.

(10) BONTEMPO, Márcio. Relatório ORION: denúncia médica sobre os perigos dos alimentos industrializados e agrotóxicos. 3. ed. Porto Alegre: L \& PM, 1986. p. 122 e ss.; FERRARI, Antenor. Agrotóxicos: a praga da dominação. Ed. Mercado Aberto-PA, 1985. p.129 e ss. 
CUSTÓDIO, Helita Barreira. Direito ambiental e questôes jurídicas relevantes. Campinas: Millennium Ed., 2004. No prelo.

. Direito à saúde e problemática dos agrotóxicos. Revista de Direito Sanitário, São Paulo, v. 2. n. 3, p. 9-35, nov. 2001.

. Princípios constitucionais da Proteção das Águas. Revista de Direitos Difusos, São Paulo, v. 4, n. 16, p. 2127-2146, nov./dez. 2002.

DALLARI, DALMO DE ABREU. Constituição e Constituinte. 3. ed. São Paulo: Saraiva, 1986.

FERRARI, Antenor. Agrotóxicos: a praga da dominação. Ed. Mercado Aberto-PA, 1985.

MAXIMILIANO, Carlos. Hermenêutica e aplicação do direito. 9. ed. Rio de Janeiro: Forense, 1979.

SANGIULIANO, Rosanna (a cura di). Diritto sanitario e servizio sanitario nazionale. 16. ed. Napoli: Simone, 2002. 